\title{
Resenha de Lukács, Georg, Conversando com Lukács: entrevista a Léo Kofler, Wolfgang Abendroth e Hans Heinz Holz, tradução de Gisieh Vianna, São Paulo, Instituto Lukács, 2014, pags. 196.
}

\author{
ALEXANDRE DE JESUS SANTOS (UESB) \\ Mestre em Memória: Linguagem e Sociedade \\ Universidade Estadual do Sudoeste da Bahia - UESB \\ Grupo de Estudos de Ideologia e Lutas de Classes - GEILC/MP/UESB \\ alexandre magno2@hotmail.com
}

Uma obra de destaque que emerge no cenário nacional brasileiro é Conversando com Lukács, do filósofo húngaro Georg Lukács (1885 - 1971). Publicada originalmente em 1967, na Alemanha, esta obra veio a público pela primeira vez no Brasil em 1969, por mediação da Editora Paz e Terra. No ano de 2014, ela ganhou uma nova edição do Instituto Lukács -IL-, traduzida por Gisieh Vianna tendo seu prefácio escrito por Talvanes Eugênio, professor da Universidade Federal de Alagoas. Com 196 páginas, o livro dispõe ainda de índices onomástico e remissivo, que ajudam a localizar as referências.

Diferentemente da primeira edição brasileira, que traz em seu corpo outros textos que não fazem parte da entrevista concedida por Lukács a Léo Kofler, Wolfgang Abendroth e Hans Heinz Holz, esta nova edição optou por publicar somente o texto original da entrevista, tal qual a edição Alemã de 1967. Isso permite ao leitor centrar sua atenção no conteúdo debatido por Lukács e seus interlocutores. Vale ressaltar ainda que a publicação desta obra por parte do IL inaugura a "Coleção Fundamentos", cujo escopo é a publicação de obras de expoentes do pensamento marxista articulados à centralidade ontológica do trabalho e a afirmação dos princípios revolucionários de transformação da sociedade, a partir, sobretudo, da retomada dos postulados fundamentais da teoria marxiana.

Poderíamos dizer que a radicalidade do pensamento lukacsiano, presente neste livro, está na consideração do trabalho como fundamento último do mundo dos homens, como diria Lessa (2012). Isso implica dizer que todos os complexos sociais só podem existir em uma relação de determinação e autonomia com a categoria trabalho, pois é este que, ao promover a transformação instrumental do mundo que rodeia o homem, cria as condições para o surgimento e o desenvolvimento de outros complexos sociais anteriormente inexistentes. Nesse sentido, todos os temas discutidos na obra possuem, como corporação nuclear, o fundamento segundo o qual todos os complexos sociais (a política, o direito, a educação etc.) só podem existir em profunda conexão com o trabalho compreendido enquanto ação teleológica. Neste sentido, Conversando com Lukács permite-nos uma primeira aproximação com os postulados fundamentais da ontologia lukacsiana. De forma geral, apesar de o livro ser composto por quatro capítulos/conversas intitulados respectivamente ser e consciência, sociedade e indivíduo, elementos para uma teoria política e balanço provisório, as conversas são amalgamadas por esta unidade estrutural.

O interessante de se observar neste livro é o lugar ocupado pela cotidianidade do pensamento de Lukács. O autor quase sempre inicia suas formulações com inferências simples sobre fenômenos que transcorrem no dia-a-dia. A partir daí, questões que aparentemente são ingênuas do ponto de vista fenomênico, ao serem analisadas a fundo pelo autor, mostram-se estruturas complexas que apresentam profundas conexões de teleologia e causalidade conectadas à totalidade social.

Lukács procura demonstrar que, por um lado, todo ser é necessariamente processo. Por conseguinte, o conhecimento produzido sobre ele carrega em si uma transitoriedade condicionada 
pelas determinações objetivas existentes do ser-assim, na mesma medida em que, em função do seu dinamismo, a formulação teórica sobre o objeto constitui apenas uma aproximação de sua essência, mas nunca a apreensão de sua totalidade; por outro, evidencia que o ser existe independentemente do conhecimento sobre ele construído, postulando, com base no primado mais elementar da filosofa materialista, a prioridade do ser sobre a consciência. É o próprio Lukács quem afirma que "há, pois, uma prioridade da realidade do real, se assim se pode dizer; e, segundo penso, devemos tentar voltar a estes fatos primitivos da vida e compreender os fenômenos complexos a partir dos fenômenos originários" (p. 27). Tal formulação implica dizer que operações complexas são realizadas na cotidianidade sem que, necessariamente, tenhamos conhecimento profundo dos seus mecanismos. Para o autor, isso ocorre pelo simples fato de que tais operações se mostram absolutamente necessárias para a reprodução cotidiana do ser social. Entrementes, se algumas operações são realizadas tacitamente, dada a sua importância para a reprodução social, outras, no entanto, exigem um profundo conhecimento, muito embora quanto mais complexo seja o fenômeno sobre o qual nos debruçamos, mais ilimitadas são as possibilidades do objeto ser conhecido diante da consciência do homem. Por isso, longe de apreender todas as suas determinações internas, o conhecimento sobre o ser é apenas aproximativo.

Partindo da obra de Marx, Lukács discorre sobre a relação intrínseca entre as formas simples de troca sobre as quais o primeiro pondera no primeiro capítulo de O Capital (2013), e sua forma no capitalismo desenvolvido. A propositura do autor, mais uma vez, envolve as relações objetivas engendradas na cotidianidade a partir de necessidades objetivas de permutas simples avançando para relações mais complexas mediadas pelo equivalente universal, o dinheiro. $O$ autor procura demonstrar que "o dinheiro nasceu ontologicamente, de maneira simples, a partir dos atos de troca. Mas os antigos ainda não tinham chegado ao ponto de poder formular esta explicação ontológica" (p. 30).

O problema da cotidianidade, bem como a produção e a reprodução dos diversos complexos sociais a partir das relações materiais da vida cotidiana é retomada pelo autor no livro Prolegômenos para uma ontologia do ser social (2010), muito embora o leitor não encontrará no livro supracitado, de forma tão explícita e com tanta riqueza de detalhes, a materialização de exemplos desta mesma magnitude. A relação existente entre essência e aparência, indivíduo e sociedade, cotidianidade e totalidade social são apenas alguns temas sobre os quais Lukács se debruça durante as conversas contidas no livro. Um aspecto bastante interessante evidenciado na primeira conversa é o esforço realizado pelo autor no sentido de demonstrar como a produção estética está amplamente ancorada, num primeiro momento, nas necessidades objetivas do ser social. A relação ontológica entre a representação do mundo e o mundo realmente existente ganha, na estética, uma relação de causalidade, sendo, portanto, um processo corrente no qual o passado é instrumentalizado pelo presente. Assim, "é claro para todos nós que este "recordar" é um processo histórico, e que, se retomo determinadas lembranças do passado, sou obrigado, exatamente por isso, a entendê-las como momentos ontológicos do vivo desenvolvimento da humanidade e não como uma articulação teórico-cognoscitiva [...]”' (p. 43).

Diferentemente de alguns autores que estão na moda no Brasil, quando se trata do debate em torno da memória, como os casos específicos de Halbwachs (2006), Le Goff (1990) Nora (1981), Lukács pensa a memória a partir de uma perspectiva ontológica. Por este prisma, a memória está relacionada ao reconhecimento de si da humanidade articulada com seu processo histórico de desenvolvimento. Longe de ser uma ação puramente individual, ou mesmo coletiva demarcada pelas estruturas herméticas e funcionais, ela se relaciona, antes, com a necessidade imanente de desenvolvimento ontológico da humanidade. Por isso, o resgate ou o refute de uma memória específica deve ser analisado a partir da relação entre o atual desenvolvimento histórico da humanidade e a necessidade ou desnecessidade de evocação de determinadas memórias.

Outro tema bastante relevante debatido neste livro é a problemática do irracionalismo presente nos 
diversos sistemas filosóficos. As formulações de Lukács sobre este aspecto vão no sentido de demonstrar que, tanto o conceito de intuição quanto o de dedução lógica, não apresentam nenhuma contraditoriedade, muito embora ambos estejam relacionados à estrutura das formulações irracionalistas que atribuem à consciência intuitiva uma certa superioridade em relação à não intuitiva. Afirma o autor que “[...] em certo sentido já na Crítica do Juízo de Kant, atribuiu-se à consciência intuitiva uma certa superioridade em face da consciência não intuitiva. [...] a superioridade da intuição foi simplesmente aceita dogmaticamente" (p. 58). Para Lukács é impossível pensar a razão e o racional "no sentido real" dissociados das conexões objetivas realizadas pelos sujeitos com o fito de reproduzir sua vida material. Longe de a razão ser compreendida como um conceito ou um ato puro, uma intuição, o racional é antes "aquilo que deriva de nosso trabalho e de nosso confronto com a realidade" (idem). A racionalidade, desta forma, é entendida em uma relação de causalidade do "se... então" no qual o "se" articula-se às situações concretas materializadas na objetividade, e o "então" a conexão racional entre ambos.

Lukács deixa claro que, se a racionalidade é o elemento explicativo da realidade, articulado com o próprio desenvolvimento das condições objetivas e, por conseguinte, da história, a relação racional do "se... então" deve ser pensada sempre dentro do seu tempo. Para o autor, a explicação de Tomás de Aquino para o feudalismo enquanto sistema que se encontrava de acordo com a razão, constituía uma expressão de racionalidade, pois achava-se dentro dos parâmetros do "se...então" do seu tempo. O que fica evidente nesta inferência é que o filosofo húngaro nunca perde de vista a processualidade da história e as conexões existentes entre a objetividade e a subjetividade. Desta forma, o irracionalismo, diferentemente da racionalidade proporcional à objetividade do seu tempo, só pode ser compreendido como uma inadequação de determinada forma de pensar e agir que não se acomoda em um determinado tempo e espaço. Argumenta Lukács que "a práxis de Marat e de Robespierre não podia ser acolhida no sistema racional das classes feudais; surge assim, da situação social, aquilo que chamamos de irracionalismo" (p. 59 - 60).

O irracionalismo moderno, por outro lado, toma forma e conteúdo totalmente diverso, tornando-se não a inadequação histórica de uma conexão racional com o movimento da realidade, mas, contraditoriamente, "um sistema específico de irracionalismo, que depois se difunde amplamente e leva a consequências que os iniciadores de tal sistema, se assim me posso exprimir, não desejavam em absoluto" (p. 60). Nesta perspectiva, diversas formulações que se tornaram conhecidas, não somente na Alemanha, mas em todo o mundo, acabam por difundir teorias irracionalistas que compreendem o mundo como um ser cuja estrutura é incognoscível. Para Lukács, não somente Weber se insere neste universo, mas também "o pragmatismo americano tem aspectos irracionalistas. Bergson está tipicamente inclinado ao irracionalismo; Croce (queira ou não) está cheio de aspectos irracionalistas. O irracionalismo, pois, não é absolutamente um fenômeno puramente alemão, mas um fenômeno internacional” (p. 61). Lukács associa a expansão do irracionalismo, assim como a da manifestação das diversas formas de alienação às novas formas de reprodução do capital, sobretudo aquelas cujo escopo encontra-se na exploração da mais-valia relativa (que, segundo o autor, é a forma predominante de extração da mais-valia, em detrimento da absoluta). Por este motivo, compreender o irracionalismo moderno pressupõe uma ampla articulação entre suas manifestações e o metabolismo social do capital.

$\mathrm{Na}$ terceira conversa, intitulada Elementos para uma política científica, muito embora Lukács reconheça o recrudescimento das lutas em função do retrocesso da consciência de classe - resultado das novas objetividades do capital, mas também da atuação decadente da socialdemocracia que tirou completamente do seu horizonte a luta pelo socialismo -, afirma categoricamente que os conflitos entre o capital e o trabalho permanecem vivos e ativos. Apesar de o capitalismo encontrar novas formas de se reproduzir, engendrando, por exemplo, o consumo de massas, fruto, principalmente da exploração da mais-valia relativa, novos problemas são colocados para as classes trabalhadoras, como é o caso do tempo fora do trabalho. Conquanto a luta pela redução da jornada de trabalho foi uma das principais pautas do movimento operário no interior do capitalismo, a subsunção total do 
trabalho ao capital faz com que até mesmo este tempo fora do trabalho seja apropriado. Evidentemente, a diminuição da jornada de trabalho tão requerida pela classe trabalhadora não significa, em absoluto, a efetivação de uma vida plena de sentindo.

O que o leitor vai encontrar neste livro, de forma geral, são conversas dessa natureza que versam sobre temas como alienação, exploração, consumo de massas, manipulação, teleologia e causalidade, indivíduo e gênero humano entre outros. Partindo quase sempre da cotidianidade, as conversas ganham dimensões complexas e profundas ao longo do debate (apesar do seu caráter nitidamente introdutório). Se por um lado, o caráter propedêutico do livro possa demonstrar-se problemático, pois muitas questões são levantadas, mas não aprofundadas, por outro, diríamos, torna-se uma leitura introdutória fundamental tanto para El Asalto a la razón e a Estética quanto para Ontologia, inclusive do ponto de vista didático, visto que conta com uma linguagem bastante compreensível e acessível, não obstante os temas complexos de que trata.

\section{Referências:}

Halbwachs, Maurice, A memória Coletiva, tradução: Beatriz Sidou, São Paulo, Centauro, 2006.

Le Goff, Jacques, História e Memória, Campinas, Editora da Unicamp, 1990.

Lessa, Sergio. Mundo dos homens: trabalho e ser social. $3^{\circ}$ ed. rev. e cor. São Paulo: Instituto Lukács, 2012.

Lukács, Georg, Conversando com Lukács: entrevista a Léo Kofler, Wolfgang Abendroth e Hans Heinz. Holr, tradução de Gisieh Vianna, São Paulo, Instituto Lukács, 2014.

Prolegômenos para uma ontologia do ser social: questões de princípios de uma ontologia boje tornada possivel, Tradução: Lya Luft e Rodnei Nascimento e supervisão editorial Ister Vaisman, São Paulo, Boitempo, 2010.

Marx, Karl, O Capital: crítica da economia política. Livro I: o processo de produção do capital; tradução: Rubens Enderle, São Paulo, Boitempo, 2013.

Nora, Pierre, "Entre a memória e a história: o problema dos lugares", in Projeto História: Revista do Programa de Estudos de Pós-graduação em História da PUC-SP, São Paulo, 1981. 